\title{
A Comparative Study between Autologous Dural Closure versus Collagen Matrix (DuraGen) Closure in Decompressive Craniectomy for Trauma
}

\author{
Rajesh Kumar Barooah' \\ Kishore Sarma ${ }^{1}$ \\ ${ }^{1}$ Department of Neurosurgery, Guwahati Medical College and \\ Hospital, Guwahati, Assam, India
}

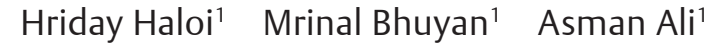

Indian J Neurotrauma:2020;17:46-49

\begin{abstract}
Keywords

- dural closure

- collagen matrix graft

- craniectomy

Introduction Neurosurgeons often deal with the problem of a complete and watertight dural closure after cerebral operative procedures. In decompressive craniectomy done for trauma, autologous grafts such as galea, temporalis fascia can be time consuming. Hence this study was undertaken to look into the outcome using collagen matrix graft for dural closure.

Aims and Objectives To study the difference between autologous dural graft closure and collagen matrix graft with respect to the time taken for closure, cerebrospinal fluid (CSF) leakage, and wound infection.

Methods This prospective study includes 30 patients who underwent decompressive craniectomy for trauma. Duraplasty with temporalis fascia graft and nonautologous collagen matrix dural patch was done by randomization. Specific time points during craniectomy and cranioplasty was calculated. Total time for the procedures and the time for dural repair and separation was calculated.

Results The use of collagen matrix in decompressive craniectomy resulted in decrease in mean operative time during the first surgery by average 45 minutes $(p<0.5)$ as compared to the use of autologous graft. There is reduction in the operating time during second surgery (cranioplasty) by 35 minutes $(p<0.5)$. The patients using collagen matrix graft did not record any CSF leakage or wound infection. Excellent uptake of the collagen by the duramater was seen.

Conclusion The use of collagen to cover the dural defect for decompressive craniectomy for trauma results in significant reduction in the operating time during the first surgery and also in cranioplasty. There is reduction in CSF leakage and hence duration of hospital stay and cost.
\end{abstract}

\begin{abstract}
Address for correspondence Hriday Haloi, MS, Department of Neurosurgery, Guwahati Medical College and Hospital, Guwahati 781032, Assam, India (e-mail: drhridayhaloi1985@gmail.com).
\end{abstract}

\section{Introduction}

Decompressive hemicraniectomy is used as a method to temporarily reduce intracranial pressure in cases of otherwise unmanageable intracranial hypertension. Following decompressive craniectomy, many surgeons prefer to create a dural expansion by implanting various materials. ${ }^{1}$ Despite 100 years of experimentation and investigation of a wide range of materials, the research for the ideal substitute still
DOI https://doi.org/

10.1055/s-0039-1698713

ISSN 0973-0508. continues. In everyday neurosurgical practice, numerous autogenic, allogenic, xenogenic, absorbable, and nonabsorbable synthetic materials have been used with varying degrees of success in the search for the perfect dural graft. ${ }^{2-6}$

Autologous grafts such as galea, temporalis fascia, or fascia lata represent an optimal dural graft substrate because they do not induce immunological or inflammatory reactions and they are nontoxic, rapidly integrated into native tissues, 
flexible, strong, easily suturable, and inexpensive. Unfortunately, it is not always possible to perform autograft using these tissues and also they are time consuming specially in decompressive craniectomy done for trauma. ${ }^{3,5,7,8}$

DuraGen (Integra Neuroscience) is a type I collagen matrix graft manufactured from bovine Achilles tendon. It is an onlay graft that does not require sutures. As no suturing is required, the operative time is significantly shortened in DuraGen closure. ${ }^{4}$

In our study, we will compare the outcome of dural closure between autologous temporalis graft and collagen matrix graft. The study aims to examine whether the use of DuraGen significantly reduce the operating time in decompressive craniectomy. It also aims to examine whether there is any reduction in operating time in those using DuraGen while doing cranioplasty (second surgery), and also whether there is any difference in cerebrospinal fluid (CSF) collection postoperatively.

\section{Aims and Objectives}

This article aims to study the difference between autologous dural graft closure and DuraGen with respect to the time taken for closure, CSF leakage, subcutaneous CSF collection, wound infection, and cost effectiveness.

\section{Materials and Methods}

This prospective study was performed in the Department of Neurosurgery, Guwahati Medical College and Hospital, Guwahati, Assam, India. A total of 30 patients who underwent decompressive craniectomy due to trauma were included in the study. Patients were randomized into two equal groups. In one group, temporalis graft was used during dural closure, and in the other, DuraGen was used. Patients were evaluated by neurological examination, Glasgow Coma Scale, and computed tomography (CT) head (P).

Decompressive craniectomy (first surgery): The operating time from incision to end of closure was calculated and noted. Also, the time taken for dural closure was noted. Time

Table 1 Patient characteristics

\begin{tabular}{|l|l|l|}
\hline & $\begin{array}{l}\text { DuraGen } \\
\text { (group 1) }\end{array}$ & $\begin{array}{l}\text { Temporalis graft } \\
\text { (group 2) }\end{array}$ \\
\hline Mean age $(y)$ & 35 & 37 \\
\hline Male & $13(86 \%)$ & $14(93 \%)$ \\
\hline Female & $2(14 \%)$ & $1(7 \%)$ \\
\hline Mean GCS & 7.2 & 7 \\
\hline
\end{tabular}

Abbreviation: GCS, Glasgow Coma Scale. taken for the separation and suturing of temporalis graft was noted. Presence of any postoperative CSF collection and wound infection were noted.

Cranioplasty (second surgery): The second surgery (cranioplasty) was done after 3 to 4 months. In all the patients, autologous skull bone flap (which was placed in the subcutaneous plane in abdomen) was used. During cranioplasty, the plane of cleavage for reinsertion of the bone was created between the myocutaneous flap and the fibrous dura-like tissue covering the brain. The bone margins surrounding the craniectomy defect were fully exposed. The time taken from the beginning to end of procedure was noted down. Also, the time taken for the separation of the dural layer was noted. In the patients receiving DuraGen, biopsy of the dural layer was done to see the uptake. Postoperative CSF collection and infection were noted.

Postoperative care and follow-up: The patients were followed up every 1 month and then at 6 months.

Statistical analysis: Mann-Whitney test and Student's $t$-test were used.

\section{Results and Observations}

The patients in whom DuraGen was used were designated as group1 and the group in whom temporalis graft was used designated as group 2 .

The mean age of patients in group 1 was 35 years while the mean age of patients in group 2 was 37 years. There were 13 males (86\%) and 2 females (14\%) in group 1, while there were 14 males (93\%) and 1 female (7\%) in group 2. Mean Glasgow Coma Scale in group 1 was 7.2 while it was 7 in group 2. The patient characteristics are shown in - Table 1 .

In all the patients, bone flap was placed in subcutaneous plane in the abdomen. All the patients in our study received perioperative antibiotics and drain was put intraoperatively that was removed within 24 hours. Postoperative CT scan was done in all the patients.

The time taken in decompressive craniectomy (first surgery) in the group using DuraGen was $134.13 \pm 4.5$ minutes (mean \pm standard deviation), while it was $179.2 \pm 3.75$ minutes in the group using temporalis graft. The difference in mean between the two procedures is 45 minutes. On using Mann-Whitney test, $p$-value was $<0.001$ and hence statistically significant. It was also found that $18 \%$ of the total surgery time was required for dural closure while using temporalis graft compared with only $4 \%$ of the surgery time while using DuraGen. Statistical analysis of the first surgery is shown in - Table 2 .

There was no wound infection recorded in our study. All the patients received postoperative intensive care unit care, antiepileptics, and antiedema measures. Extensive chest and limb physiotherapy was done in all patients. There was four mortality (13\%) recorded in our study. All the patients who

Table 2 Statistical analysis of first surgery

\begin{tabular}{|l|l|l|l|l|l|}
\hline & Material & $N$ & Mean & $\begin{array}{l}\text { Standard } \\
\text { deviation }\end{array}$ & $\begin{array}{l}\text { Standard error of the } \\
\text { mean }\end{array}$ \\
\hline \multirow{2}{*}{ First surgery, min } & DuraGen & 15 & 134.13 & 4.549 & 1.175 \\
\cline { 2 - 6 } & Temporalis graft & 15 & 179.20 & 3.745 & 0.967 \\
\hline
\end{tabular}


Table 3 Statistical analysis of cranioplasty

\begin{tabular}{|l|l|l|l|l|l|}
\hline & Material & $N$ & Mean & $\begin{array}{l}\text { Standard } \\
\text { deviation }\end{array}$ & $\begin{array}{l}\text { Standard error } \\
\text { (mean) }\end{array}$ \\
\hline \multirow{2}{*}{ Cranioplasty time } & DuraGen & 12 & 134.83 & 4.687 & 1.353 \\
\cline { 2 - 6 } & Temporalis Graft & 12 & 177.50 & 4.543 & 1.311 \\
\hline $\begin{array}{l}\text { Dural separation } \\
\text { time }\end{array}$ & DuraGen & 12 & 25.17 & 2.329 & 0.672 \\
\cline { 2 - 6 } & Temporalis Graft & 12 & 48.50 & 2.316 & 0.669 \\
\hline
\end{tabular}

died had a mean age of more than 40 years. Two of them had previous history of cardiovascular diseases.

The second surgery (cranioplasty) was done after 3 to 4 months. Preoperative CT scan was done in all the cases. Out of the 30 patients undergoing decompressive craniectomy, 24 (80\%) were undertaken for cranioplasty. Out of the 30 patients, 4 patients (13\%) expired, and 2 (6\%) were lost to follow-up. Out of the 24 patients undergoing cranioplasty, $12(50 \%)$ were those in whom DuraGen was used previously and 12 (50\%) in whom temporalis graft was used. Autologous skull bone flap was used while doing cranioplasty in all the cases. The time taken for the dural preparation in the DuraGen group was $25.17 \pm 2.3$ minutes (mean \pm standard deviation). The time taken for dural preparation in the other group was $48.5 \pm 2.36$ minutes. The total time taken for cranioplasty in the DuraGen group was $134.83 \pm 4.6$ minutes (mean \pm standard deviation), while in the other group it was $177.5 \pm 4.54$ minutes. Also, $27 \%$ of the operating time was used in dural separation in the group using temporalis graft while $18 \%$ of the operating time was used in dural separation in the DuraGen group. On using Student's t-test, $p$-value was $<0.001$ and hence there is significant difference in the time taken between the two groups. Statistical analysis is shown in - Table 3.

There were two patients (16\%) in the second group who developed subcutaneous CSF collection postoperatively. However, it resolved completely after 1 month. No wound infection was reported after cranioplasty.

\section{Discussion}

Despite several years of study and analysis, the search for the perfect dural substitute continues. Over the past 50 years, autologous grafts (pericranium, fascia lata, fat, muscle, and temporalis fascia) were often preferred as an inexpensive, nonimmunogenic graft that fused with native dura. ${ }^{7,9}$ However, the available tissue is often limited or damaged and requires a second surgical incision., ${ }^{9,10}$

The unique advantages of biological and synthetic grafts support their current usage. First, xenografts were used more often in decompressive craniectomy for evacuation of traumatic subdural hematoma; these products incorporate into native dura and often do not require suturing, which can be useful in trauma cases requiring fast closure. ${ }^{11}$ Animal-derived collagen matrices that do not require suturing, like TissuDura (Baxter) and DuraGen, have additional implications for reduction of operative time and placement in difficult locations. ${ }^{12}$ Danish et al $^{12}$ reported shorter operating room times when using nonsutured xenografts rather than allografts, which minimizes anesthesia-related complications and medical costs.

There is significant reduction in the time taken for decompressive craniectomy and cranioplasty in our study in the group using DuraGen. Horaczek et $\mathrm{al}^{13}$ in their study had similar findings of significant reduction in time in hemicraniectomy using DuraGen as dural substitute. In our study, the difference in mean between the two procedures is 45 minutes. Hence, a significant amount of time was saved by using DuraGen as dural substitute as compared with allogenic graft. There was also difference in the time taken for dural repair while using the two procedures. In the second surgery (cranioplasty), the time taken for the dural layer separation was significant between the two groups. DuraGen was found to be completely uptaken by the dural layer as the whole dural layer during cranioplasty was found to be uniform. Hence, the time taken during the dural separation on using DuraGen was found to be significantly less than while using temporalis fascia (where more adhesion and more time taken was encountered). Hence, it was found that the time taken during cranioplasty was significantly less in the DuraGen group.

Subcutaneous CSF collection/CSF leakage was only found in the group where temporalis graft was being used. This was due to the dissection done to separate the dural layer during cranioplasty. The higher CSF leakage rate resulted in higher hospital stay in those patients and hence higher cost and morbidity. However, after 1-month follow-up, there was no residual CSF collection. Similar finding were observed by Danish et al $^{12}$ and Narotam et al. ${ }^{14}$

\section{Conclusion}

There is a significant reduction in the time for doing decompressive craniectomy while using collagen matrix (DuraGen) for dural closure as compared with autologous graft (temporalis graft). Significant reduction in time for doing decompressive craniectomy might mean in itself a reduction in surgical trauma as well as duration of hospital stay. While doing cranioplasty, the time taken for the dural separation as well as the total time of cranioplasty in those using DuraGen was significantly less. CSF leakage was not found in the group using DuraGen. Hence, it resulted in better outcome, early discharge, and a lesser hospital cost.

\section{Conflict of Interest}

None. 


\section{References}

1 Ostendorf AP, Connolly AM. Medical management of eosinophilic meningitis following bovine graft duraplasty for Chiari malformation Type I repair: case report. J Neurosurg Pediatr 2013;12(4):357-359

2 Sandoval-Sánchez JH, Ramos-Zúñiga R, de Anda SL, et al. A new bilayer chitosan scaffolding as a dural substitute: experimental evaluation. World Neurosurg 2012;77(3-4):577-582

3 Lam FC, Kasper E. Augmented autologous pericranium duraplasty in 100 posterior fossa surgeries-a retrospective case series. Neurosurgery 2012;71(2, Suppl Operative):ons302-ons307

4 Gazzeri R, Galarza M, Alfieri A, Neroni M, Roperto R. Simple intraoperative technique for minor dural gap repair using fibrin glue and oxidized cellulose. World Neurosurg 2011;76(1-2):173-175

5 Malliti M, Page P, Gury C, Chomette E, Nataf F, Roux FX. Comparison of deep wound infection rates using a synthetic dural substitute (neuro-patch) or pericranium graft for dural closure: a clinical review of 1 year. Neurosurgery 2004;54(3):599-603

6 Cappabianca P, Esposito F, Magro F, et al. Natura abhorret a vacuo-use of fibrin glue as a filler and sealant in neurosurgical "dead spaces". Technical note. Acta Neurochir (Wien) 2010;152(5):897-904
7 Hoover DA, Mahmood A. Ossification of autologous pericranium used in duraplasty. Case report.J Neurosurg 2001;95(2):350-352

8 Stevens EA, Powers AK, Sweasey TA, Tatter SB, Ojemann RG. Simplified harvest of autologous pericranium for duraplasty in Chiari malformation Type I. Technical note. J Neurosurg Spine 2009;11(1):80-83

9 Yamada K, Miyamoto S, Nagata I, et al. Development of a dural substitute from synthetic bioabsorbable polymers. J Neurosurg 1997;86(6):1012-1017

10 Rosen CL, Steinberg GK, DeMonte F, et al. Results of the prospective, randomized, multicenter clinical trial evaluating a biosynthesized cellulose graft for repair of dural defects. Neurosurgery 2011;69(5):1093-1103

11 HoraczekJA,ZierskiJ, Graewe A.Collagen matrix in decompressive hemicraniectomy. Neurosurgery 2008;63(1, Suppl 1):ONS176ONS181, discussion ONS181

12 Danish SF, Samdani A, Hanna A, Storm P, Sutton L. Experience with acellular human dura and bovine collagen matrix for duraplasty after posterior fossa decompression for Chiari malformations. J Neurosurg 2006;104(1, Suppl):16-20

13 HoraczekJA,ZierskiJ, Graewe A.Collagen matrix in decompressive hemicraniectomy. Neurosurgery 2008;63(1, Suppl 1):ONS176ONS181, discussion ONS181

14 Narotam PK, van Dellen JR, Bhoola KD. A clinicopathological study of collagen sponge as a dural graft in neurosurgery. J Neurosurg 1995;82(3):406-412 